\title{
Identifying the Prevalence and Risk Factors Associated With Uncontrolled Diabetes (Type 2) in Al Buraimi Governorate, Sultanate of Oman
}

\author{
Amal Ali Khamis Al Makhmari ${ }^{1}$, Muhammad Muqeet Ullah², \\ Fatma Sulieman Salim Al Alawi ${ }^{1} \&$ Khalifa Darwish Al Saadi ${ }^{3}$ \\ ${ }^{1}$ Department of Professional development and Career guidance, DGHS, Al Buraimi Governorate, Ministry of \\ Health, Oman \\ ${ }^{2}$ Regional Epidemiologist Directorate of Communicable Disease Surveillance and Control, DGHS Al Buraimi \\ Governorate, Ministry of Health, Oman \\ ${ }^{3}$ Health Information Officer Buraimi Polyclinic, DGHS Al Buraimi Governorate, Ministry of Health, Oman \\ Correspondence: Amal Ali Khamis Al Makhmari, Sr. Staff Nurse, Department of Professional development and \\ Career guidance, Directorate General of Health Services, Al Buraimi Governorate, Ministry of Health, P.O. Box:8, \\ 512, Sultanate of Oman. E-mail: amalali3200@gmail.com
}

Received: July 21, 2018 Accepted: September 24, 2018 Online Published: October 13, 2018

doi:10.5539/gjhs.v10n11p39

URL: https://doi.org/10.5539/gjhs.v10n11p39

\begin{abstract}
Background: People with poorly controlled diabetes are likely to have shortened life, diabetes related complications and also reduced quality of life. WHO-EMRO region is considered to be the highest prevalence region accounted 43 million people. Among GCC countries, Oman has reported increased number of cases in recent years.

Objective: To identify the prevalence and risk factors associated with uncontrolled diabetes (Type 2) in a diabetic setting of Al Buraimi Polyclinic, AL Buraimi Governorate, Oman.

Methodology: This Cross sectional retrospective study was conducted in diabetic clinic of Al Buraimi Polyclinic of primary health care, Al Buraimi Governorate Oman between January-April 2015. This study enrolled all diabetic patients type $2(\mathrm{~N}=1164)$ who were registered during the period 2010-2014 in the polyclinic. Data was retrieved from the electronic diabetic register and patient's electronic records in a diabetic setting at Al Buraimi Polyclinic. Descriptive statistics were applied to analyze the data. Differences between the groups were analyzed by using Chi-square test in SPSS 16 with $p$ value $\leq 0.05$ significance level.

Results: Prevalence of Uncontrolled Diabetes Mellitus Type 2 was found to be 623 (54\%) among 1164 registered

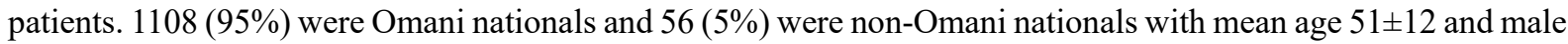
predominance $632(54 \%)$ with higher significance $(\mathrm{p}$-value $=0.009)$. A significant association was found between treatment and glycemic control $(p$-value $=0.000)$ with $926(80 \%)$ were on oral hypoglycemic agents. Moreover, $\mathrm{HbAlc}$ was significantly associated with total cholesterol, Low density lipoprotein and Triglyceride with ( $p$-value $=0.000) .629(54 \%)$. Diabetic patients were having family history as a common risk factor.
\end{abstract}

Conclusion: Uncontrolled diabetes mellitus with prevalence $>50 \%$ implies an alarming challenge to health care system. An intervention should be focused on patient's education, emphasizing on life modification strategies. Furthermore, multidisciplinary approach is needed for the effective care of diabetes in primary health care.

Keywords: prevalence, poor glycemic control, HbAlc, risk factors, primary health care

\section{Introduction}

Diabetes is a chronic, metabolic disease characterized by the elevated levels of blood glucose (or blood sugar), which leads over time to serious damage to the heart, blood vessels, eyes, kidneys, and nerves. The most common is type 2 diabetes, usually in adults, which occurs when the body becomes resistant to insulin or doesn't make enough insulin. $90 \%$ of people with diabetes have type 2 diabetes. In the past three decades, the prevalence of type 2 diabetes has raised dramatically in countries of all income levels. There is a globally agreed target to halt the rise in diabetes and obesity by 2025 . WHO Global report on diabetes demonstrates that the number of adults living 
with diabetes has almost quadrupled since 1980 to 422 million adults. In 2012 alone diabetes caused 1.5 million deaths. Its complications can lead to heart attack, stroke, blindness, kidney failure and lower limb amputation. The risk of type 2 diabetes is determined by interplay of genetic and metabolic factors. Ethnicity, family history of diabetes, and previous gestational diabetes combine with older age, overweight and obesity, unhealthy diet, physical inactivity and smoking increases its risk. Overweight and obesity are the strongest risk factors for type 2 diabetes (Global Report on Diabetes, 2016).

WHO-EMRO region is considered to be highest prevalence region accounted 43 million people. In reference to prevalence of diabetes in WHO, Oman is considered as one of the GCC countries that has reported increased number of cases. Oman reported, 113,000 diabetic cases in the year 2000 and which is expected to be 343,000 by 2030 (WHO-EMRO Region Diabetes Program).

In 2013, the annual health report of Oman accounted 119 new cases in Al Buraimi Governorate, Oman. As a result, the high rate of new cases registered per year will ultimately lead to large burden on health care system. (Annual Health Report Ministry of Health Oman, 2013). In Oman, according to " diabetes mellitus management guidelines for primary health care, $\mathrm{HbA} 1 \mathrm{C}$ should be $<7 \%$ to rank the glcaemic control as optimal which is similar to most of the international guidelines. (Al Balushi, Al Haddabi, Al Zakwani, \& Al Zaabi, 2014).

Non-communicable diseases cause $83 \%$ of all mortality in Sultanate of Oman. Non-communicable diseases include: cardiovascular disease (49\%), Cancers (11\%), Diabetes (7\%), Respiratory Diseases (3\%) and another diseases (13\%). Such diseases drain around $52 \%$ of the expenditure of health and therapeutic burden, in addition to its massive and serious impact on the type and level of daily life, causing an endless negative effect to society, and also limiting the activity of citizens within the sultanate and cost the Ministry of health (MOH) a great payment from its annual budget. They also affect the effectiveness of health system levels, because they require attention and intensive follow-up as a result of the growing burden of complications associated with these diseases. (Directorate of Research and Studies - March 2014 Health research priorities).

Al Buraimi Governorate is situated in the North West corner of the Sultanate of Oman, adjacent to the borders with UAE. Governorate of Al Buraimi consists of three wilayats: Al Buraimi, Mahdah and Al Sunainah. According to the census of the annual health report of Oman 2012; the population of the Al Buraimi Governorate was 92,235, among them 2,085 were registered as diabetic.

By studying the risk factors for uncontrolled diabetes, the quality of health services can be improved in the region. Hence, the aim of this study was to determine the prevalence of poor glycemic control among type 2 diabetes mellitus attending in Al Buraimi Polyclinic at AL Buraimi Governorate and to determine the risk factors associated with it.

\section{Methodology}

\subsection{Design and Study Population}

This Cross sectional retrospective study was conducted in Al Buraimi Governorate and data was retrieved from the electronic diabetic register and patient's electronic record at Al Buraimi Polyclinic, Al Buraimi Governorate, Oman between January-April 2015. This study enrolled all the diabetic patients type $2(\mathrm{~N}=1164)$ who were registered during period 2010-2014 in the Al Buraimi polyclinic after meeting the inclusion and exclusion criteria.

\subsection{Inclusion Criteria}

Included above 12 years old subjects who were registered in the National Diabetes Register; had the HbAlc test more than $7 \%$ and were on diabetic medications.

\subsection{Exclusion Criteria}

Those who were transferred, expired, controlled patients, pediatric cases below 12 years old and had gestational diabetes were excluded from the study.

\subsection{Data Collection}

Data collection sheet was designed to extract the data from the electronic register which contain data such as (age, sex, BMI, HbA1c, complications, co-morbidity, risk factors and other relevant information about the Management). According to WHO in 2006 define Good diabetes control as an HbA1C level (gelucose in blood attached to hemoglubine) below a target level 6.5-7.5\%. In Oman according to diabetes mellitus management guidelines for primary health care, $\mathrm{HbAlC}$ is classified as good $<7$, Borderline 7-8 and Poor $>8$ to rank the glycemic control.

\subsection{Analysis}


Descriptive statistics were used to analyze the data. Differences between groups were analyzed by using Chi-square test. For differences among variables, a $p$-value of $\leq 0.05$ was considered statistically significant. Analyses were performed using SPSS version 16.

\subsection{Ethical Consideration}

Ethical Approval for the study was obtained from the Regional Research and Ethics Committee at Al Buraimi Governorate, Oman. Confidentiality of the record was maintained during entire period of the study.

\section{Results}

Out of the total 1164 patients, 1108 (95\%) were Omani nationals, among them 54\% had poor glycemic control $(\mathrm{HbAlc}>8)$ whereas $56(5 \%)$ were non Omani nationals with $51 \%$ poor glycemic control. Mean age \pm SD was $51 \pm 12$.It was found that $532(46 \%)$ were females, with $50 \%$ poor glycemic control. On other hand, males constituted $632(54 \%)$ with $57 \%$ had poor glycemic control with significant association (p-value $=0.009)$.

Hypertension and Heart disease were reported in $579(50 \%)$ and $117(10 \%)$ respectively and were statistically insignificant. In management, majority of patients were found to be on oral hypoglycemic agents $80 \%$, followed by insulin $14 \%$ while $5 \%$ subjects were on combined oral hypoglycemic agent and insulin whereas, diet alone contributed $1 \%$. A significant association between treatment and glycemic control ( $\mathrm{p}$-value $=0.000)$. HbAlc was significantly associated with total cholesterol, Low density lipoprotein and Triglyceride with ( $p$-value $=0.000)$. Whereas, association between BMI and glycemic control was also found to be insignificant ( $(p$ value $=0.486)$.

The study also explored that the most common diabetic complications were found to be Retinopathy $14 \%$, Nephropathy (proteinuria) $13 \%$ and $8 \%$ with other complications while $66 \%$ patients had no complications reported. However, there was no significant association found between complications and glycemic control (HbA1C, $p$-value $=0.212$ ); (see Table 1: Variables among registered diabetic patients $(\mathrm{N}=1164)$.

Table 1. Variables among registered diabetic patients $(\mathrm{N}=1164)$ : Variables versus $\mathrm{HbAlc}$

\begin{tabular}{|c|c|c|c|c|c|}
\hline Variable & All & Good HbA1c $<7$ & Borderline HbA1c 7-8 & Poor HbA1c $>8$ & p-value \\
\hline \multicolumn{6}{|l|}{ Nationality } \\
\hline Omani & $1108(95 \%)$ & $283(26 \%)$ & $230(20 \%)$ & $595(54 \%)$ & 0.791 \\
\hline Non Omani & $56(5 \%)$ & $14(25 \%)$ & $14(24 \%)$ & $28(51 \%)$ & \\
\hline Age, mean $\pm S D$,years & $51 \pm 12$ & & & & \\
\hline \multirow[t]{4}{*}{ Age group } & $<40$ & 34.36 & 34.10 & 33.46 & \\
\hline & $40-49$ & 44.60 & 45.16 & 44.61 & 0.406 \\
\hline & $50-59$ & 54.49 & 53.59 & 54.20 & \\
\hline & $>60$ & 67.42 & 67.02 & 66.97 & \\
\hline \multicolumn{6}{|l|}{ Gender } \\
\hline Female & $532(46 \%)$ & $135(25 \%)$ & $132(25 \%)$ & $265(50 \%)$ & 0.009 \\
\hline Male & $632(54 \%)$ & $162(26 \%)$ & $112(17 \%)$ & $358(57 \%)$ & \\
\hline \multicolumn{6}{|l|}{ Co morbidity } \\
\hline HTN & $579(50 \%)$ & $145(25 \%)$ & $126(22 \%$ & $308(53 \%)$ & 0.789 \\
\hline Heart Disease & $117(10 \%)$ & $27(23 \%)$ & $20(17 \%)$ & $70(60 \%)$ & 0.333 \\
\hline \multicolumn{6}{|l|}{ Complications } \\
\hline No complication & $767(66 \%)$ & $207(27 \%)$ & $165(21 \%)$ & $395(51 \%)$ & \\
\hline Retinopathy & $159(14 \%)$ & $34(21 \%)$ & $34(21 \%)$ & $91(57 \%)$ & 0.212 \\
\hline Proteinuria & $147(13 \%)$ & $41(28 \%)$ & $25(17 \%)$ & $81(55 \%)$ & \\
\hline Other complications & $91(8 \%)$ & $15(16 \%)$ & $20(22 \%$ & $56(62 \%)$ & \\
\hline
\end{tabular}




\begin{tabular}{|c|c|c|c|c|c|}
\hline \multicolumn{6}{|l|}{ Management } \\
\hline Diet & $9(1 \%)$ & $5(56 \%)$ & $1(11 \%)$ & $3(33 \%$ & \\
\hline OHA & $926(80 \%)$ & $265(29 \%)$ & $202(21 \%)$ & $459(50 \%)$ & 0.000 \\
\hline Insulin & $168(14 \%)$ & $18(11 \%)$ & $35(21 \%)$ & $115(68 \%)$ & \\
\hline Combination(OHA+Insulin) & $61(5 \%)$ & $9(15 \%)$ & $6(10 \%)$ & $46(75 \%)$ & \\
\hline \multicolumn{6}{|l|}{ BMI mean } \\
\hline$<25 \mathrm{~kg} / \mathrm{m}^{2}$ & 22.7 & 22.8 & 22.5 & 22.6 & 0.486 \\
\hline$\geq 25 \mathrm{~kg} / \mathrm{m}^{2}$ & 31.8 & 31.8 & 31.9 & 31.8 & \\
\hline \multicolumn{6}{|l|}{ Cholesterol mean } \\
\hline$<5.2 \mathrm{mmol} / \mathrm{L}$ & 4.18 & 4.102 & 4.13 & 4.26 & 0.000 \\
\hline$\geq 5.2 \mathrm{mmol} / \mathrm{L}$ & 6.00 & 5.82 & 5.94 & 6.06 & \\
\hline \multicolumn{6}{|l|}{ LDL mean } \\
\hline$<2.6 \mathrm{mmol} / \mathrm{L}$ & 1.98 & 1.96 & 1.97 & 2.00 & 0.000 \\
\hline$\geq 2.6 \mathrm{mmol} / \mathrm{L}$ & 3.54 & 3.47 & 3.24 & 3.61 & \\
\hline \multicolumn{6}{|l|}{ HDL mean } \\
\hline$\leq 0.9 \mathrm{mmol} / \mathrm{L}$ & 0.784 & 0.79 & 0.81 & 0.76 & 0.229 \\
\hline$>0.9 \mathrm{mmol} / \mathrm{L}$ & 1.245 & 1.23 & 1.25 & 1.24 & \\
\hline \multicolumn{6}{|l|}{ TG mean } \\
\hline$\geq 2.3 \mathrm{mmol} / \mathrm{L}$ & 3.50 & 3.23 & 3.68 & 3.54 & 0.000 \\
\hline$<2.3 \mathrm{mmol} / \mathrm{L}$ & 1.37 & 1.26 & 1.35 & 1.44 & \\
\hline
\end{tabular}

The study results showed that $629(54 \%)$ diabetic patients were having family history as a common risk factor followed by $140(12 \%)$ obesity and $151(13 \%)$ smoking. However, the relation between the risk factors and HbA1c were insignificant (see Table 2: risk factors among diabetic patients).

Table 2. Risk factors among registered diabetic patients

\begin{tabular}{lll}
\hline Risk Factor & Percentage & p-value \\
\hline Family History & $629(54 \%)$ & 0.952 \\
Obesity & $140(12 \%)$ & 0.324 \\
Smoking & $151(13 \%)$ & 0.191 \\
\hline
\end{tabular}

HbA1C among patients showed that 623 (54\%) patients had poor glycemic control, 244(21\%) had borderline and 297 (25) \% patients had good glycemic (see Figure 1). 


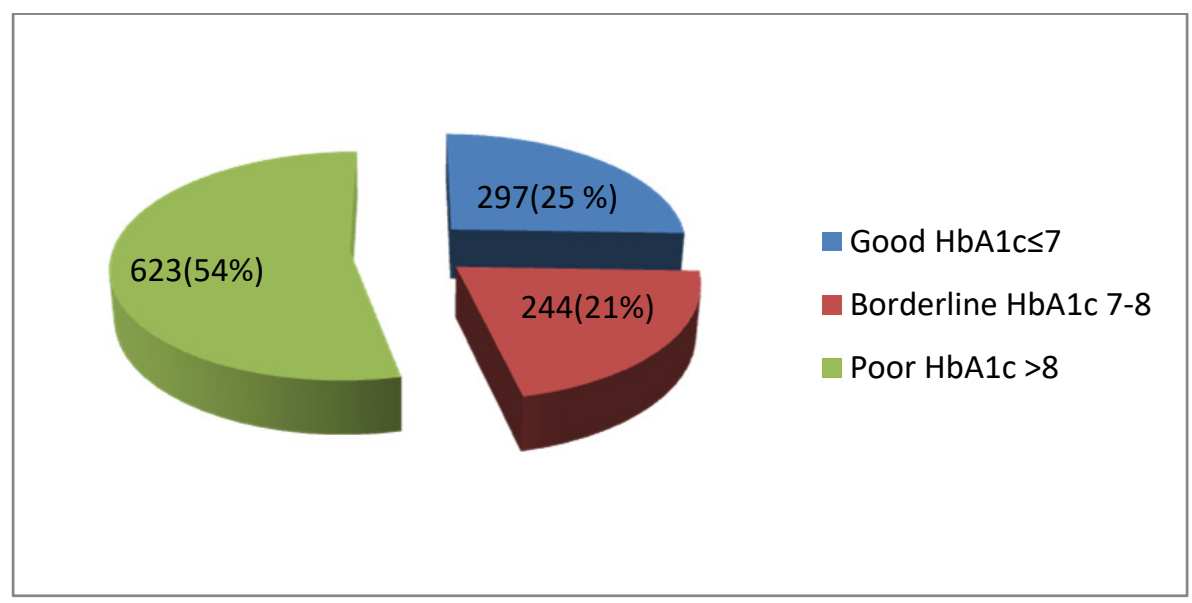

Figure 1. Number and Percentage of patients with glycemic control HbAlc rank

\section{Discussion}

One of the challenges in controlling diabetes is integrating services and improving the quality of health care provided to people. However, this challenge is needed to be addressed and managed by primary health care institutions. The result of this study showed that the majority of our subjects did not attain adequate glycemic control as $54 \%$ of them had $\mathrm{HbAl} 1 \mathrm{c}>8 \%$. This result was expected due to the progressive nature of the disease and because studies from Oman and other parts of the world had demonstrated similar finding whereas study from Pakistan revealed that the prevalence of uncontrolled diabetes (HbAlc is equal or more than 8 ) was $38.9 \%$. Additionally, it showed that there was no association between uncontrolled diabetes, BMI and age group] (Siddiqui, Avan, Mahmud, Nanan, Jabbar, \& Assam, 2015).

Majority of patients in this current study were above 50 years and had higher HbAlc than the younger patients. On the other hand, previous study conducted in Oman had shown younger adults had significantly higher HbA1c among primary health care patients with Type 2 Diabetes Mellitus (Al-Lawati, Barakat, Al Maskari, Elsayed, Al Lawati. \& Mohammed, 2012).

Similar study was conducted in Al-Dakhiliya region of Oman where they found that the older patients had controlled their blood sugar more efficiently than younger patients which is reverse to our study (Venugopal, Kunju, Al Harthy, \& Al Zadjali, 2008).

During this study, a significant association was found between cholesterol, LDL and triglycerides with HbA1c $(\mathrm{p}=0.000)$. This strong association underlines the usefulness of this test to assess glycemic control in diabetes care. On the other hand, there was insignificant association between glycemic control and BMI $(p$ value $=0.486)$.

A study in Hawaii about factors associated with poor glycemic control among diabetes patient indicated that duration of diabetes, age, number of medications, morbidity, and type of insurance coverage were risk factors for sustained poor glycemic control. Patients with these characteristics may need additional therapies and targeted interventions to improve glycemic control (Juarez, Sentell, Tokumaru, Goo, Davis, \& Mau, 2012), whereas the result of this study explored that $21 \%$ of subjects have no risks factors, whereas $54 \%$ were having family history, $12 \%$ obesity and $13 \%$ smoking. However, the relation between the risk factors and $\mathrm{HbA} 1 \mathrm{c}$ was insignificant. In 2012 a cross-sectional survey was done in Saudi Arabia about the factors contributing to non-compliance among diabetics attending primary health care centers, showed that the rate of noncompliance of diabetic patients was high. The main reasons for this were non-adherence to the anti-diabetic treatment, the appointment schedule, and the exercise and diet regimen. Also, it showed that the level of education also played an important role in adherence to medical advice (Khan, Al Badul Lateef, Al Aithan, Bu Khamseen, Al Ibrahim, \& Khan, 2012).

In our study, majority of the subjects, $926(80 \%)$ were on oral hypoglycemic agents with $459(50 \%)$ among them had poor glycemic control. Also, it was found that $61(5 \%)$ patients with combination therapy (OHA and Insulin) had poor glycemic control, 46(75\%). This study showed significant association between treatment and glycemic control $(p$-value $=0.000)$ whereas study conducted in Jordan found that the highest level of poor glycemic control was among patients on combination of oral anti-diabetic agent and insulin (92.5\%) (Khattab, Khader, Al-Khawaldeh, \& Ajlouni, 2010).

Our study findings might be a stimulus to conduct large scale studies, to assess the quality of diabetes care at the 
primary health care institutions in the region and to reduce social and economic burden of the disease in the society.

\section{Conclusion}

It was concluded that the uncontrolled diabetes mellitus with prevalence $>50 \%$ among poorly controlled diabetic patients implies an alarming challenge to health care system as well as threat to public health. The study highlighted that the higher $\mathrm{HbA1} \mathrm{c}$ was significantly associated with lipids profile, management and gender. There was insignificant association between $\mathrm{HbAlc}$ and risks factors (family history, obesity, and smoking) which needed further prospective research to understand other determinants of poor glycemic control. The importance of this study was to highlight the current local situation regarding risk factors leading to uncontrolled diabetes type 2 in primary health care setting. Multidisciplinary approach is needed for effective care of diabetes in primary health care.

\section{Authors Contribution}

AAKAM composed the manuscript and planned the study; MMU worked on methodology; FSSAA did the data collection and revision of manuscript; and KDAS accomplished the interpretation of results and statistical analysis.

\section{Acknowledgements}

The author would like to thank the administration of Buraimi Polyclinic and concern staff who helped in the completion of the study staff who is working hard in caring diabetic patients.

\section{Competing Financial Interests Declaration}

Author and Corresponding Authors have no actual or potential competing financial interest and research was approved by Regional Research and Ethical Review \& Approve Committee, Ministry of Health, Oman.

\section{References}

Al Balushi, K. A., Al-Haddabi, M., Al-Zakwani, I., \& Al Za'Abi, M. (2014). Glycemic control among patients with type 2 diabetes at a primary health care center in Oman. Primary Care Diabetes, 8(3), 239-243. https://doi.org/10.1016/j.pcd.2014.01.003

Al-Lawati, J. A., Barakat, M., Al Maskari, M., Elsayed, M., Al Lawati, A., \& Mohammed, A. (2012). HbA1c Levels among primary health care patients with Type 2 Diabetes Mellitus in Oman. Oman Med J, 27(6), 465-470. https://doi.org/10.5001/omj.2012.111

Diabetes Global Report. (2016). Retrieved from http://www.who.int/diabetes/global-report/en/

Juarez, D. T., Sentell, T., Tokumaru, S., Goo, R., Davis, J. W., \& Mau, M. M. (2012). Factors Associated with Poor Glycemic Control or wide Glycemic Variability Among Diabetes patients in Hawaii, 2006-2009. Prev Chronic Dis., 9, 120065. https://doi.org/10.5888/pcd9.120065

Khan, A., Al Badul Lateef. Z., Al Aithan, M., Bu Khamseen, M., Al Ibrahim, I., \& Khan, S. (2012). Factors contributing to non-complaince among diabetics attending primary health centers in the Al Hasa district of Saudi Arabia. Journal of Family \& Community Medicine, 19(1), 26-32. https://doi.org/10.4103/2230-8229.94008

Khattab, M., Khader, Y., Al-Khawaldeh, A., \& Ajlouni, K. (2010). Factors Associated with Poor Glycemic Control among Patients with Type 2 Diabetes. Journal of diabetes and its complications, 24, 84-89. https://doi.org/10.1016/j.jdiacomp.2008.12.008

Siddiqui, F. J., Avan, B. I., Mahmud, S., Nanan, D., Jabbar, A., \& Assam, P. N. (2015). Uncontrolled Diabetes Mellitus: Prevalence and Risk Factors Among People with Type 2 Diabetes Mellitus in An Urban District of Karachi, Pakistan. Diabetes Res and Clinical Practice, 107(1), 148-156. https://doi.org/10.1016/j.diabres.2014.09.025

Utilization of health services. Annual Health Report 2013, 7, 7-38; 8, 8-80, Ministry of Health, Oman.

Venugopal, S., Kunju, R., Al Harthy. S., \& Al Zadjali, N. (2008). Hemoglobin A1c in Muscat, Oman - A 3 year study. Oman Med J, 23(3), 170-172.

World Health Organzation [WHO]. (2006). Diabetes Program, Country and regional data on diabetes, WHO Eastern Mediterranean Region. Retrieved from http://www.emro.who.int/health-topics/diabetes/index.html 


\section{Copyrights}

Copyright for this article is retained by the author(s), with first publication rights granted to the journal.

This is an open-access article distributed under the terms and conditions of the Creative Commons Attribution license (http://creativecommons.org/licenses/by/4.0/). 